\title{
A laboratory model of a replenished magma chamber
}

\author{
Herbert E. Huppert \\ Department of Applied Mathematics and Theoretical Physics, University of Cambridge, Silver Street, Cambridge CB3 9EW \\ (England) \\ and

\section{J. Stewart Turner} \\ Research School of Earth Sciences, Australian National University, Canberra, A.C.T. 2600(Australia) \\ Received November 18,1980 \\ Revised version received February 16, 1981
}

\begin{abstract}
It has recently been suggested that periodic influxes of hot but heavy magma into the base of a basaltic magma chamber can remain isolated from the rest of the chamber while the new magma cools and crystallization proceeds. When thermal equilibrium is almost complete, the suspended crystals settle out and the residual, less dense liquid can then mix with the fluid above. In the present paper the basic fluid-dynamical processes underlying this model have been investigated in laboratory experiments using aqueous solutions. The lower layer was hot $\mathrm{KNO}_{3}$ solution, for which saturated solutions become less dense as the temperature decreases. With a cold, deeper layer of less dense $\mathrm{NaNO}_{3}$ or $\mathrm{K}_{2} \mathrm{CO}_{3}$ above the lower layer, there was strong convective transfer of heat through a sharp interface separating the layers, at a rate which is predicted here drawing on previous studies carried out with oceanographic applications in mind. Once crystallization began, non-equilibrium effects became important and the observed temperatures differ somewhat from those predicted. In the experiments crystals grew mainly from the bottom rather than while in suspension, but this is not an essential aspect of the model. The important fact is that the density of the residual liquid in the lower layer decreased until it became equal to that of the upper layer, and then the interface broke down so that the two layers mixed thoroughly together, leaving a layer of $\mathrm{KNO}_{3}$ crystals at the base. No crystallization at all occurred when the hot input liquid was forced to mix initially with the cold solution already in the chamber.
\end{abstract}

\section{Introduction}

During the last decade there has been an increasing interest in the fluid-dynamical processes involved in the formation of various geological structures, in particular layered igneous intrusions and exhalative massive sulphide ore deposits. Some of these studies have followed up the consequences of fluid processes which have previously been neglected in geological models (see, for example, the discussion of the fine-scale layering in the Skaergaard intrusion [1], which is based on the phenomenon of chemical oscillations arising because of the different rates of thermal and chemi- cal diffusion). Other studies have concentrated on laboratory experiments developed to explore possible influences of the "double-diffusive" processes on exhalative ore deposits [2] and on layering and differentiation in magma chambers [3-5]. These latter experiments aimed to explain how a vertical density and compositional stratification could arise from crystallization processes and the accompanying boundary-layer flows set up by side-wall cooling in a magma chamber which is initially homogeneous.

In this paper, we discuss an experimental investigation of a magma chamber subject to quite different initial conditions. Huppert and Sparks 
$[6,7]$ recently suggested a theoretical model of the evolution of some basaltic magma chambers, the essentials of which are as follows. Periodically there is an influx of new magnesium-rich magma into the base of the chamber. Due to compositional differences the new magma is heavier than the resident magma, even though it is also hotter. It thus ponds at the base of the chamber and cools because of the heat transfer across the relatively thin non-turbulent interface separating the new magma from the layer above it. This heat transfer drives turbulent convective motions in both layers and during this time there is a negligibly small compositional transfer across the interface. As the lower layer cools, olivine crystals form. Initially the root-mean-square turbulent velocities in the lower layer greatly exceed the (low Reynolds number) free-fall velocity of the crystals and they are kept in suspension by the convective motion. The calculations of Huppert and Sparks indicated that not until the two layers have almost reached thermal equilibrium do the crystals separate from the lower layer. Sparks et al. [8] calculated that the density of picritic basaltic magma decreases with decreasing temperature as olivine crystallizes out, though below a certain temperature the density of basaltic magmas often increases with decreasing temperature as other crystals, notably plagioclase, form. It follows that once the olivine crystals have separated it is possible for the remaining liquid in the lower layer to be less dense than the upper basalt layer and consequently to rise up and mix with it. For details of the model the reader is referred to Huppert and Sparks [7] and for a pictorial summary to fig. 2 of Huppert and Sparks [6].

The actual suspension of the crystals owing to the turbulent motion is not an essential aspect of the model. The purpose of the experiments to be reported in this paper was to investigate the fundamental aspects of the process described above. Specifically, we wished to examine the rather novel fluid-mechanical concept that a hot, dense layer of liquid can be introduced under a cooler, lighter layer, whereupon the liquid in the lower layer cools, produces crystals, becomes lighter and overturns into the upper layer.

To this end, we used as the lower layer a

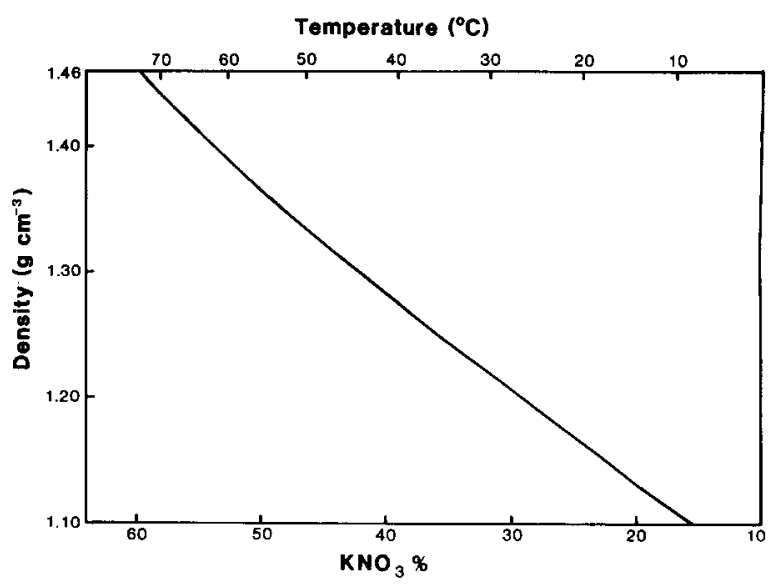

Fig. 1. The density of saturated aqueous $\mathrm{KNO}_{3}$ as a function of concentration or temperature.

solution of technical grade $\mathrm{KNO}_{3}$. The density of saturated $\mathrm{KNO}_{3}$ at thermodynamic equilibrium as a function of temperature and concentration of dissolved $\mathrm{KNO}_{3}$ (expressed as wt.\%) is graphed in Fig. 1 from data compiled from the International Critical Tables (Volume III, p. 106) [9]. The format of this figure is identical to fig. 1 of Huppert and Sparks [6], which graphs the melt density of picritic liquids as a function of temperature and $\mathrm{MgO}$ content. In both figures the density of the residual liquid decreases as the temperature decreases. Other chemicals that have a large variation of saturation density with temperature, such as $\mathrm{Na}_{2} \mathrm{SO}_{4}$, might have been used in a laboratory experiment, but $\mathrm{KNO}_{3}$ was readily available and inexpensive.

For the upper layer we used a solution of either $\mathrm{K}_{2} \mathrm{CO}_{3}$ or $\mathrm{NaNO}_{3}$. The solubility of $\mathrm{KNO}_{3}$ is strongly decreased by the presence of $\mathrm{K}_{2} \mathrm{CO}_{3}$ and weakly increased by the presence of $\mathrm{NaNO}_{3}$, as shown in Fig. 2 prepared from Kremann and Zitek [10]. The change in solubility of $\mathrm{KNO}_{3}$ in the presence of the component in the upper layer played a role at the interface between the two layers. Because we wished to minimise this additional effect, most of the experiments used $\mathrm{NaNO}_{3}$ in the upper layer. This also had the advantage that we had available an atomic absorption spectrophotometer which allowed us to measure accurately changes in the concentration of $\mathrm{Na}^{+}$and $\mathrm{K}^{+}$in the upper layer. 


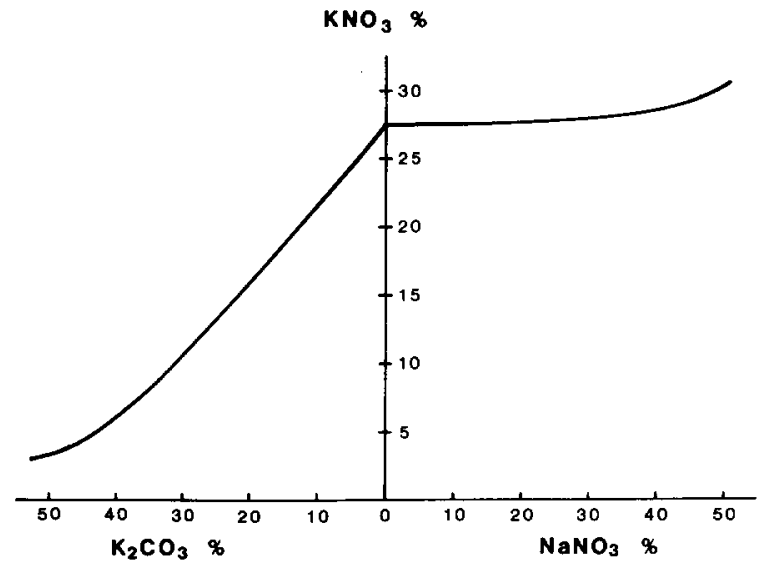

Fig. 2. The maximum solubility of $\mathrm{KNO}_{3}$, expressed as wt. $\%$, as a function of the amount of $\mathrm{K}_{2} \mathrm{CO}_{3}$ or $\mathrm{NaNO}_{3}$ present in solution at $24.2^{\circ} \mathrm{C}$.

The details of the experimental techniques are presented in the next section, followed by a presentation of the results and our interpretation of them. The third section develops a quantitative analysis of the temperature and density of the two layers as a function of time. The analysis is shown to agree with the experimental results in the early stages, but significant nonequilibrium effects invalidate the analysis near to the time when the layers mix. The fourth section summarizes our results and discusses their geological relevance.

\section{The experiments}

The experiments were carried out in a Perspex container measuring $40 \times 20 \times 30 \mathrm{~cm}$ high. Liquid could be introduced into the container either at the top or through a flexible tube leading to a 0.7 $\mathrm{cm}$ diameter hole in the centre of the base. A circular disc of radius $8 \mathrm{~cm}$ rested on thin wire legs $0.7 \mathrm{~cm}$ high and was placed centrally over the hole in order to allow the incoming liquid to flow smoothly onto the bottom.

The upper layer liquid was prepared, cooled and poured into the container to a nominal depth of $22 \mathrm{~cm}$. The lower-layer liquid was prepared and heated, a small amount of blue dye was added for visualisation purposes and it was then introduced below the upper layer to a nominal depth of $6 \mathrm{~cm}$. This input took about 2 minutes. Glass thermistor beads of $0.1 \mathrm{~cm}$ radius were positioned nominally 4 and $9 \mathrm{~cm}$ from the bottom and connected to a chart recorder in order to give continuous readings of temperature in the upper and lower layers. In some experiments a submarine-shaped glass weight $10 \mathrm{~cm}$ long with a radius of $0.9 \mathrm{~cm}$ and a mass of $55.66 \mathrm{~g}$ was suspended in the lower layer and its weight recorded. From this measurement the den-

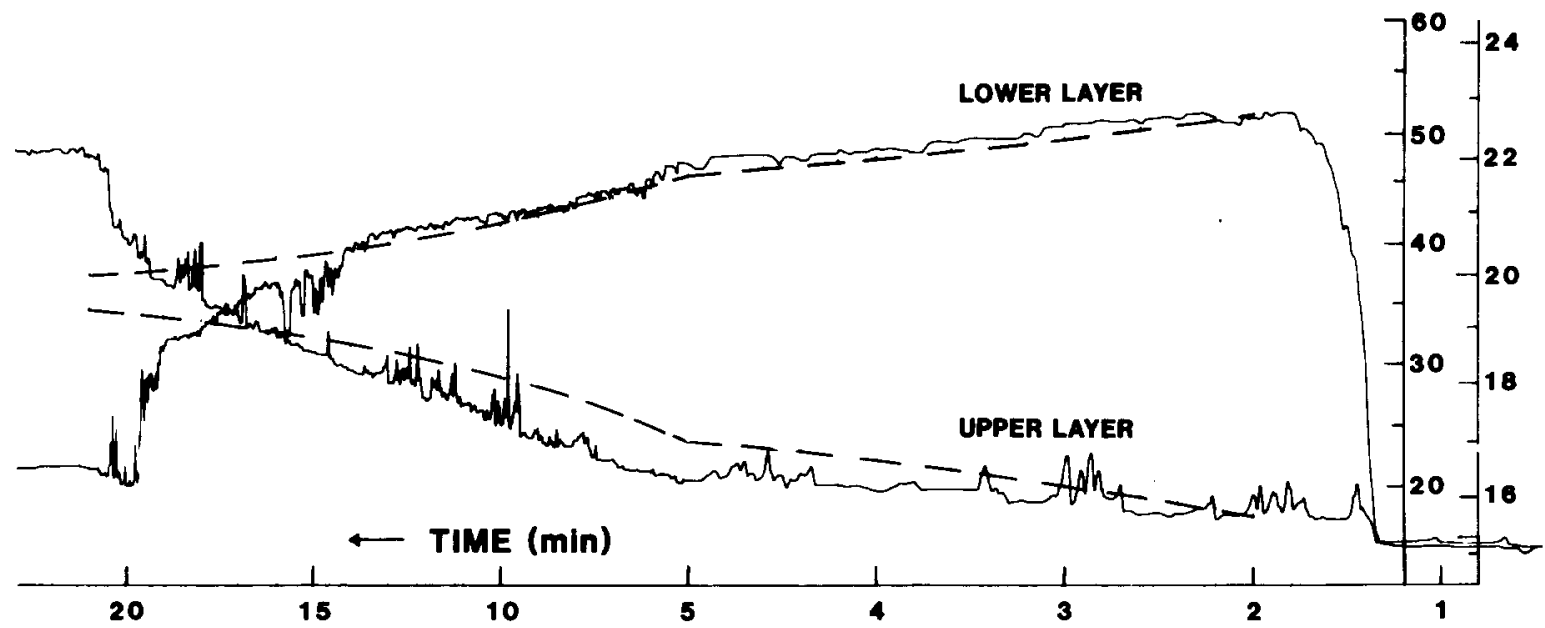

Fig. 3. The temperature traces obtained from the thermistor beads placed in the upper and lower layers, containing $\mathrm{NaNO}_{3}$ and $\mathrm{KNO}_{3}$ respectively, as a function of time. Dashed lines: the theoretical expressions (3). Lower and upper layer properties were: initial temperatures 63 and $14^{\circ} \mathrm{C}$; initial concentrations 46 and $37 \%$; initial densities 1.33 and $1.29 \mathrm{~g} \mathrm{~cm}^{-3}$; and depths 5.8 and $21.2 \mathrm{~cm}$. Note the change in the time scale at 5 minutes and that time runs from right to left. 


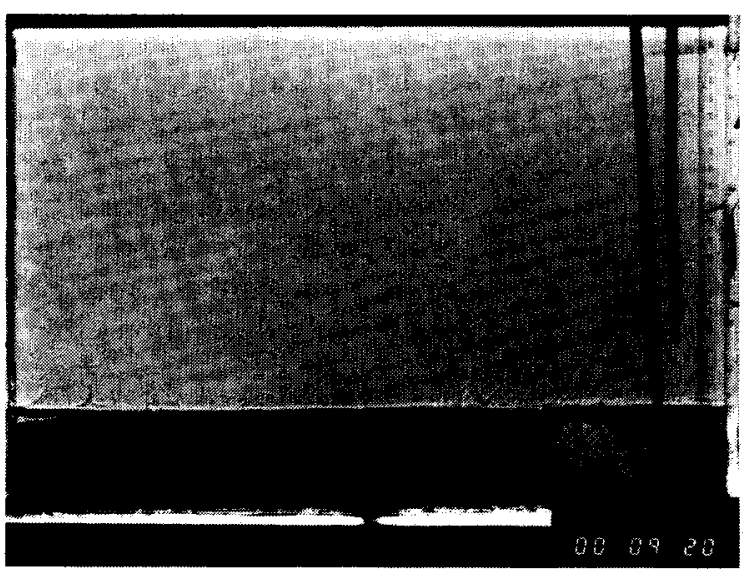

a

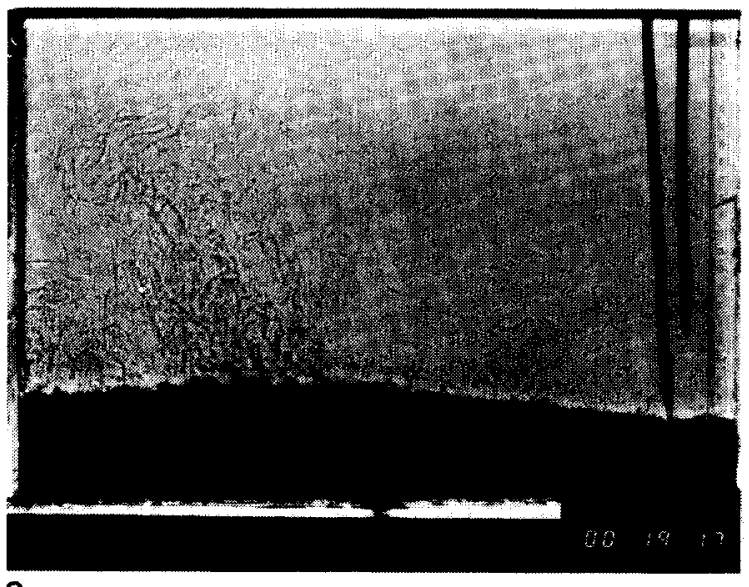

C

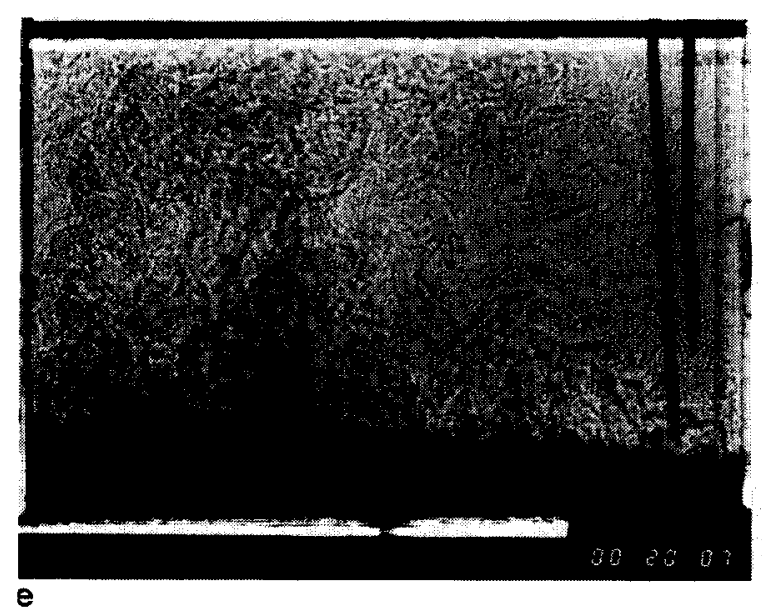

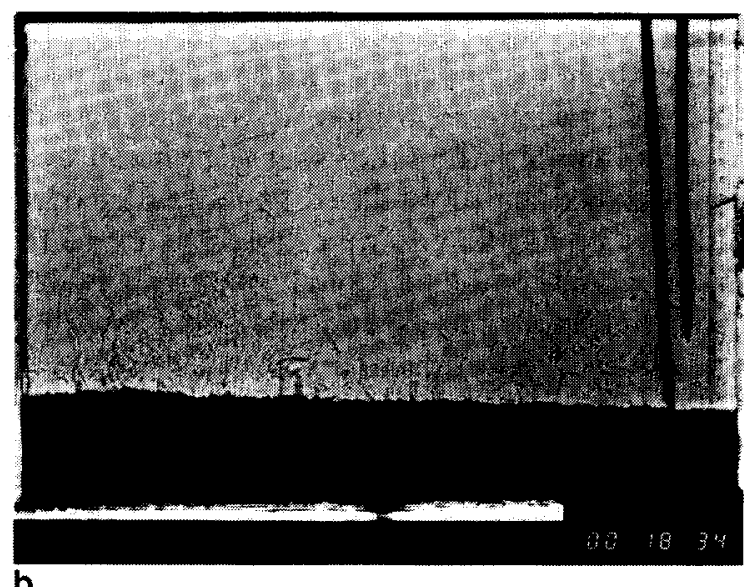

b
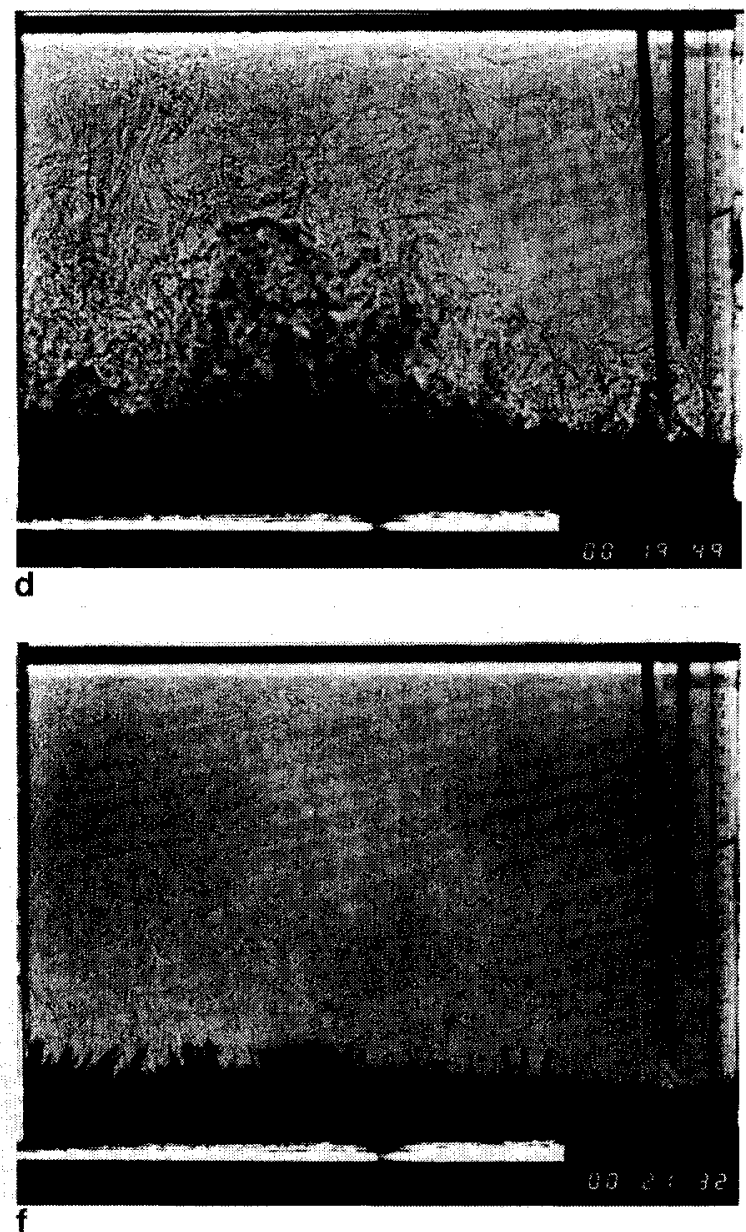

Fig. 4. Shadowgraph views of the experiment described in Fig. 3 at the times indicated on the clock in hours, minutes and seconds since the commencement of the input of the lower layer. 
sity of the liquid in the lower layer was monitored. In one experiment samples were withdrawn frequently from the upper layer for subsequent analysis for chemical composition. It was not possible to obtain samples from the lower layer because the liquid cooled and crystallized as it was removed. Motions in the liquids were observed using the shadowgraph technique. Colour photographs were taken during all the experiments and a cine film was made of one of them.

By varying the temperatures and compositions of the two layers the time scales and the amount of crystallization could be altered. We shall now de-

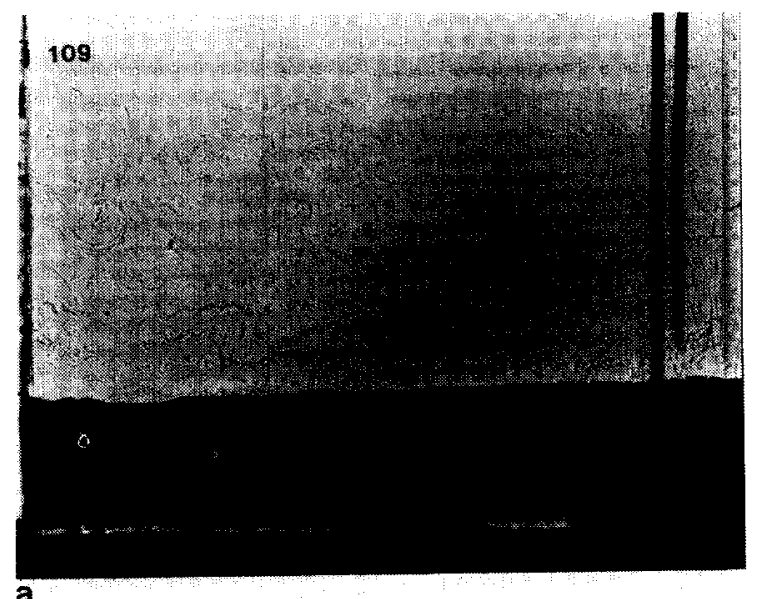

a

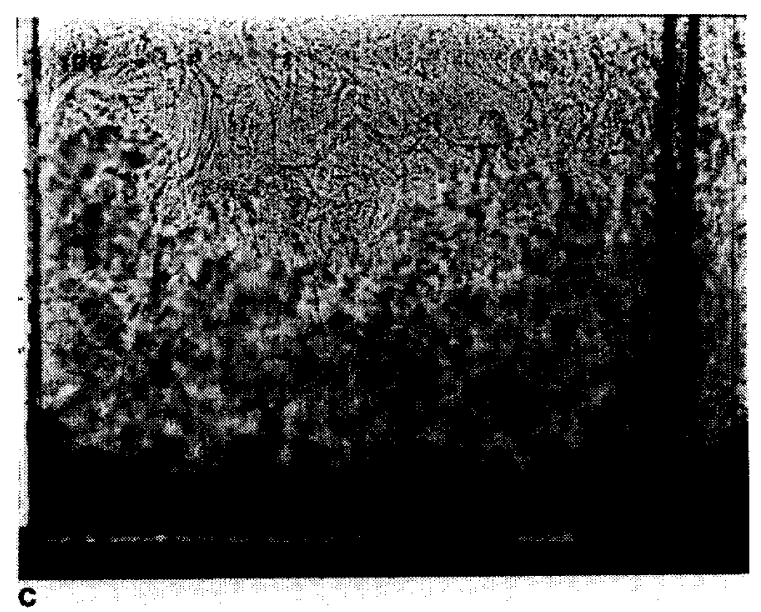

scribe the processes operating in the experiments, using all the information gained from the several experiments rather than describing any particular experiment in detail. It is worth keeping in mind as we do so the results of our "control" experiments in which we rapidly mixed samples of the two fluids in the proportions corresponding to the respective layer depths. In no case did any crystals form at all, since the mixed solution was not saturated with either solute.

After the lower-layer liquid had been introduced into the container it began to cool by transferring heat to the upper layer, as seen from the
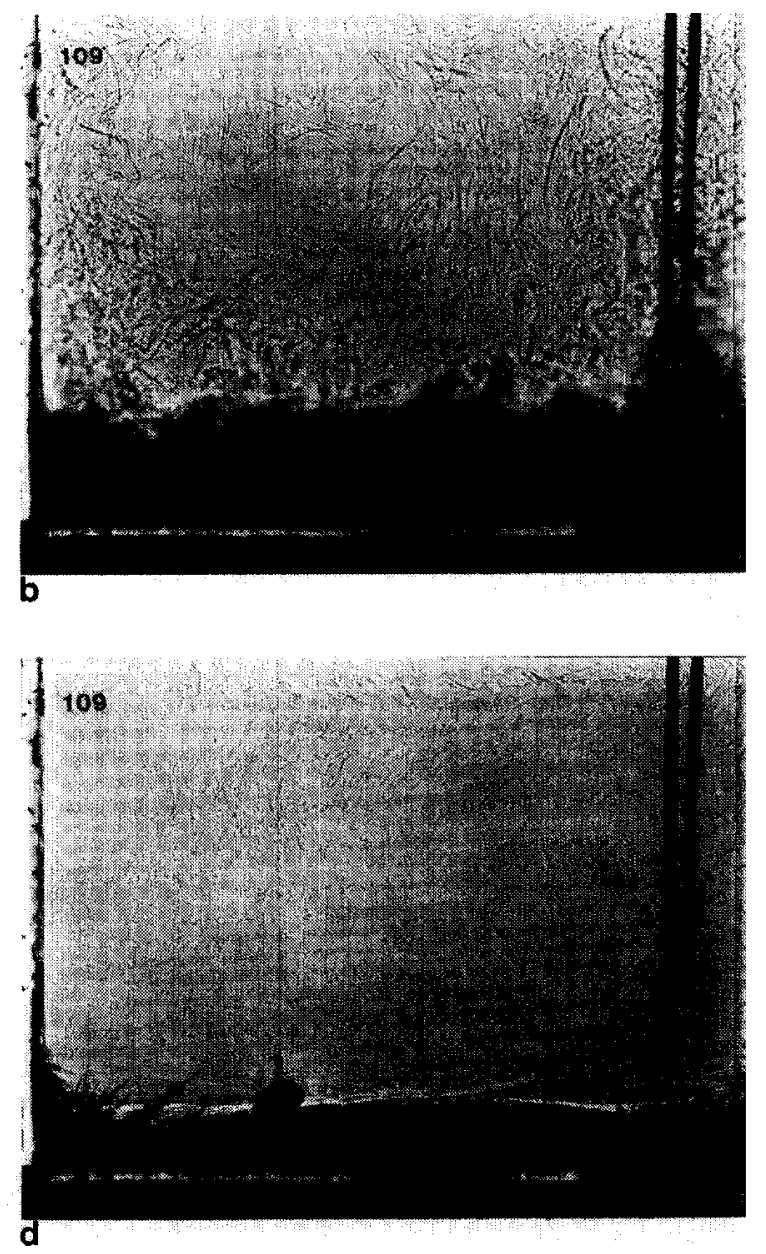

Fig. 5. Shadowgraph views as in Fig. 4 of an experiment with $\mathrm{KNO}_{3}$ and $\mathrm{K}_{2} \mathrm{CO}_{3}$. The submarine-shaped glass weight used to determine the density of the lower layer can be seen in all the views. Lower and upper layer properties were: initial temperatures 46 and $15^{\circ} \mathrm{C}$; initial concentrations 37 and $24 \%$; initial densities 1.26 and $1.23 \mathrm{~g} \mathrm{~cm}^{-3}$; and depths 7.0 and $22.0 \mathrm{~cm}$. 
records of the temperature of the two layers as a function of time presented in Fig. 3, taken directly from the strip-chart recorder that we used. (Note that the container was uninsulated but the heat transfer through the sidewalls was negligible.) Convective plumes were evident in both layers (see Figs. 4 and 5) and the fluctuations in the temperature traces of Fig. 3 indicated that the convection in the early stages of the experiments was thermally driven. The density of the lower layer increased with increasing time as the temperature of the lower layer decreased, as seen in Figs. 6 and 7. After some time numerous very small crystals could be seen being transported with the convective motion in the lower layer. With further time larger crystals were observed in the lower layer. These formed initially in the corners and then grew all over the base when the upper layer contained $\mathrm{NaNO}_{3}$. The larger crystals formed at the interface and migrated to the bottom when the upper layer contained $\mathrm{K}_{2} \mathrm{CO}_{3}$. For some time while these larger crystals were growing the density of the lower layer continued to increase linearly with temperature as indicated in Fig. 7. We interpret this to

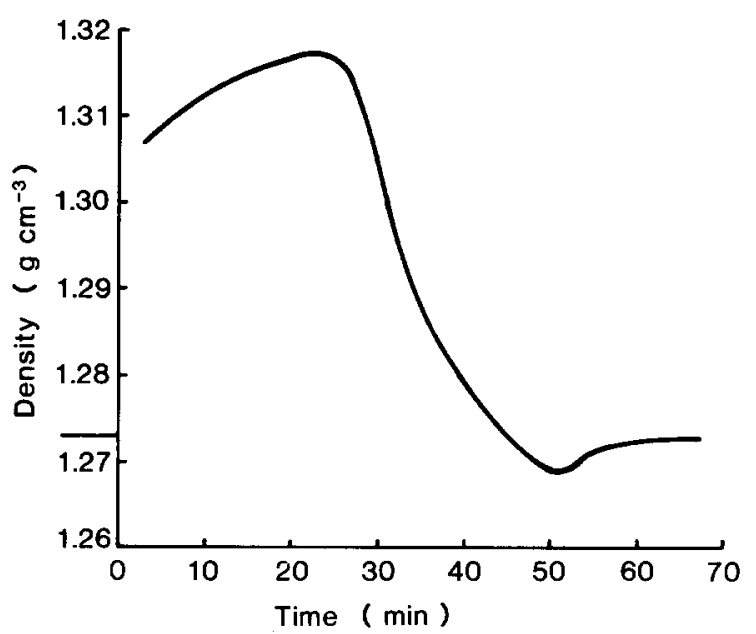

Fig. 6. The density of the lower layer, as determined from weighting a submarine-shaped glass bob, as a function of time for an experiment with $\mathrm{KNO}_{3}$ and $\mathrm{NaNO}_{3}$. The interface began to breakdown when the density of the lower layer reached its minimum value. Lower and upper layer properties were: initial temperatures 65 and $17^{\circ} \mathrm{C}$; initial concentrations 43 and $35 \%$; initial densities 1.30 and $1.27 \mathrm{~g} \mathrm{~cm}^{-3}$; and depths 7.0 and $21.6 \mathrm{~cm}$.

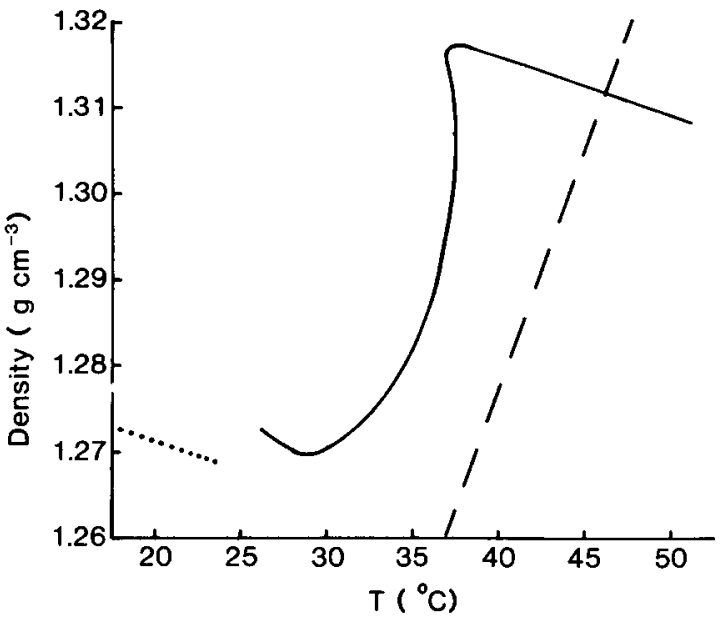

Fig. 7. The density of the lower layer, determined as in Fig. 6, as a function of the temperature of the lower layer, determined from the thermistor held in the lower layer, for the same experiment as in Fig. 6. Dashed curve: density of saturated $\mathrm{KNO}_{3}$ as a function of temperature (transcribed from Fig. 1). Dotted curve: density of the upper layer as a function of the temperature of the upper layer, as determined from data in the International Critical Tables, Vol. III, p. 82.

signify that non-equilibrium effects were important and that the lower layer became supersaturated.

At some point in time the density of the lower layer began to decrease dramatically. Strong compositionally driven convection was evident in the lower layer with relatively light liquid streaming past the crystals protruding from the bottom (Figs. $4 \mathrm{a}$ and $5 \mathrm{a}$ ). Subsequently, the interface between the two layers became very irregular on a small scale and millimetre-wide plumes of the blue-dyed lower layer could be seen protruding into the upper layer (Fig. 4b). Within a few minutes of the irregularities on the interface first occurring the density of the lower layer became equal to that of the upper layer. The interface broke down and the lower-layer liquid rose into the upper layer and mixed quite thoroughly with it (Figs. 4d,e and $5 b, c)$. Two or three minutes after the initial breakdown of the interface the (now one) layer of liquid into which the crystals now protruded was remarkably homogeneous (Fig. 4f). In the subsequent hours and days the crystals slowly dissolved, leaving a thin heavy layer of $\mathrm{KNO}_{3}$. 


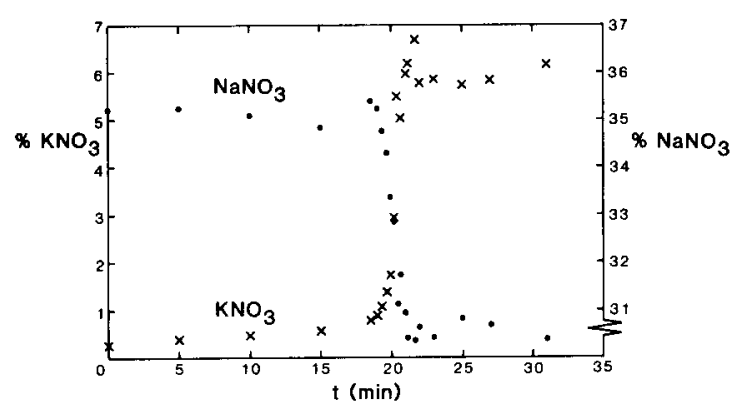

Fig. 8. The concentrations of $\mathrm{KNO}_{3}$ ( $\times$, left-hand axis) and $\mathrm{NaNO}_{3}$ (9, right-hand axis) in the upper layer as a function of time for the experiment described in Fig. 3.

During one experiment, samples were removed from the upper layer while sweeping the end of a syringe horizontally $22 \mathrm{~cm}$ from the bottom; i.e. from nominally the mid-depth of the original upper layer. We hoped thereby to obtain a horizontal average and smooth out the local fluctuations. The results of the subsequent analysis are shown in Fig. 8. Before the interface broke down there was a slight gradual increase in the amount of $\mathrm{KNO}_{3}$ in the upper layer added to the (much greater) amount already present as an impurity. As the interface broke down and a single layer was formed, the $\mathrm{KNO}_{3}$ concentration increased, with some evidence of an overshoot. X-ray crystallographic analysis of the crystals subsequent to the experiments indicated that they were pure $\mathrm{KNO}_{3}$.

\section{Theory}

The concept of a hot and heavy layer of liquid underlying a colder and lighter layer has been extensively investigated over the last fifteen years because of its oceanographic applications. A review of the work in this field is contained in Chapter 8 of Turner [11]. Turner documents in section 8.3 the theory and experiments which indicate that in terms of their contribution to the density, the compositional flux across the interface is smaller than the heat flux by a factor $\tau^{1 / 2}$, where $\tau=\kappa_{\mathrm{S}} / \kappa_{\mathrm{T}}$ and $\kappa_{\mathrm{S}}$ and $\kappa_{\mathrm{T}}$ are the molecular diffusivities of solute and heat respectively. For our experiments $\kappa_{\mathrm{S}} \simeq 1.8 \times 10^{-5} \mathrm{~cm}^{2} \mathrm{~s}^{-1}$ and $\kappa_{\mathrm{T}}$ $\simeq 1.5 \times 10^{-3} \mathrm{~cm}^{2} \mathrm{~s}^{-1}$. Thus $\tau^{1 / 2} \simeq 0.11$. It is hence reasonable to assume that the concentrations of the upper and lower layer remain constant, though a more complex calculation allowing for the slight change could be made. The justification of this assumption can be seen in Fig. 6 where the relative change in density (absolute change divided by the mean density) while the lower layer is cooling and becoming heavier is shown to be $0.0069(0.009 / 1.31)$. The associated compositional contribution should thus have been $\simeq 0.0069 \times$ $0.11=0.00076$, which can be neglected in comparison with the value of $\simeq 0.3$, the initial contribution made by the $\mathrm{KNO}_{3}$ in the lower layer. This prediction of an insignificant change is consistent with the data presented in Fig. 8.

Using the flux relationships determined by Huppert [12] from Turner's [13] experimental data with $\mathrm{NaCl}$ as the solute in the lower layer, we can write down the two equations governing the time rate of change of the temperatures $T_{\mathrm{L}}$ and $T_{\mathrm{U}}$ of the lower and upper layers before crystallization commences. The equations are:

$\frac{\mathrm{d} T_{\mathrm{L}}}{\mathrm{d} t}=-\mathrm{r}^{-1} \frac{\mathrm{d} T_{\mathrm{U}}}{\mathrm{d} t}=-A\left(T_{\mathrm{L}}-T_{\mathrm{U}}\right)^{10 / 3}$

with:

$A=0.32\left(\frac{g \kappa_{\mathrm{T}}^{2}}{\nu}\right)^{1 / 3} \alpha^{7 / 3} \rho_{0}^{2} /\left(h_{\mathrm{L}} \sigma^{2}\right)$

where $g$ is the acceleration due to gravity, $\nu$ is the kinematic viscosity, $\alpha$ is the coefficient of expansion, $\rho_{0}$ is the mean density of the two layers, $h_{\mathrm{L}}$ and $h_{\mathrm{U}}$ are the depths of the lower and upper layers respectively, $r=h_{\mathrm{L}} / h_{\mathrm{U}}$ and $\sigma$ is the density excess of the lower layer over that of the upper layer due solely to compositional effects. With initial temperatures $T_{\mathrm{L}}(0)$ and $T_{\mathrm{U}}(0)$ in the lower and upper layers respectively at some (arbitrary) time datum $t=0$, the solutions to (1) are:

$$
\begin{aligned}
T_{\mathrm{L}}(t)= & T_{\mathrm{L}}(0)+\left\{\left[\Delta_{0}^{-7 / 3}\right.\right. \\
& \left.\left.+\frac{7}{3} A(1+r) t\right]^{-3 / 7}-\Delta_{0}\right\} /(1+r) \\
T_{\mathrm{U}}(t)= & T_{\mathrm{U}}(0)-r\left\{\left[\Delta_{0}^{-7 / 3}\right.\right. \\
& \left.\left.+\frac{7}{3} A(1+r) t\right]^{-3 / 7}-\Delta_{0}\right\} /(1+r)
\end{aligned}
$$


where $\Delta_{0}$, the initial temperature difference between the two layers, is given by:

$\Delta_{0}=T_{\mathrm{L}}(0)-T_{\mathrm{U}}(0)$.

Superimposed on the chart recordings of temperature presented in Fig. 3 are the relationships (3) with $\alpha=5.0 \times 10^{-4} \mathrm{C}^{-1}$ and $\kappa_{\mathrm{T}}=1.5 \times 10^{-3}$ $\mathrm{cm}^{2} \mathrm{~s}^{-1}$. The agreement between theory and experiment is seen to be very good. The results obtained in quite a different context can therefore be carried across to the present application. Once crystallization becomes more rapid, however, and the density of the lower layer begins to decrease, the relationships (3) depart from the observed temperature, as is seen to occur after approximately 13 minutes in the experimental results depicted in Fig. 3. An analysis of the subsequent temperature evolution incorporating crystallization effects would require an investigation and quantification of non-equilibrium effects, which determine the density of the residual liquid as a function not only of temperature but also of the history of the cooling process. Such a study is beyond the scope and purpose of the current paper, but see Buckley [14 pp. 7-11 and particularly fig. 4].

\section{Discussion and conclusions}

The results of our laboratory experiments have given strong direct support to the main physical assumptions on which Huppert and Sparks [6,7] based their theoretical model of the evolution of some basaltic magma chambers. We have shown that when a hot but heavy influx of new fluid is introduced into a chamber it ponds at the base and the progress of crystallization can be quite different from the case where there is supposed to be complete mixing initially.

The isolation of the inflowing fluid in a bottom layer does two things. First, it allows this fluid to cool much more rapidly, by convective transfer of heat to the deep, cooler fluid above through the sharp interface separating them, rather than solely by conduction through the side boundaries. The measured rates of change of temperature in both layers are in good agreement with theory in the initial stages before crystallization dominates. Second, there is very little transfer of the dissolved components through the interface, so that cooling of the lower layer leads to rapid saturation and crystallization of the solute in this bottom layer. As crystals form, the residual fluid becomes less dense, but the lower layer can nevertheless remain denser than the deeper overlying layer for a considerable time. Thus whether crystals remain suspended (as was postulated for magma chambers) or form immediately on, or settle onto, the bottom does not lead to an essential difference between the prototype and the laboratory experiments.

Eventually, as crystallization proceeds, the density of the lower layer can decrease sufficiently for it to approach that of the upper layer. We have not so far been able to model theoretically this stage of our experiments since we are not able to take non-equilibrium (supersaturation) effects properly into account. When the two densities become equal, there is a rapid breakdown of the interface and an intimate mixing occurs between the two layers. A layer of crystals having a horizontal top is left at the bottom. The concentration of the lower layer fluid in the mixture is much less than it would have been if complete mixing had taken place initially, because of the amount which has crystallized out. This is the main feature used by Huppert and Sparks [6] to explain the low $\mathrm{MgO}$ content of magmas erupted at mid-ocean ridges compared with that characteristic of more primitive source magmas.

In conclusion, it is worth contrasting two other features of the "completely mixed" model of a magma chamber with the results of the present experiments. If the fluid added from below is heavier than that already in the chamber, then a great deal of energy would be needed to mix the two completely. Even if the heavy fluid were projected upwards at a considerable velocity, or put in at some other level, it would fall to the bottom after some mixing with the fluid above (see Turner [15] or Turner and Gustafson [2]). Further, the dilution of the input fluid in the well-mixed chamber can be so great that it is not saturated, nor can it become so until the whole chamber has cooled considerably. Our control experiments, in which we mixed samples of the fluids in the two layers in 
the correct proportions and at the initial temperatures, have shown explicitly how crystallization can be completely prevented by this mixing.

\section{Acknowledgements}

It is a pleasure to acknowledge the able assistance offered us by Derek Corrigan and Ross Wylde-Browne in performing the experiments and preparing the figures. We are grateful for comments on an earlier draft of the manuscript from Paul Linden, Alex McBirney, Dan McKenzie and Steve Sparks. The experiments and writing of the paper were completed while H.E.H. was a Visiting Fellow at the Research School of Earth Sciences, A.N.U. He gratefully acknowledges the stimulating research atmosphere provided by members of the School and the financial support received from the A.N.U. and from the Royal Society.

\section{References}

1 A.R. McBirney and R.M. Noyes, Crystallization and layering of the Skaergaard intrusion, J. Petrol. 20 (1979) 487-554.

2 J.S. Turner and L.B. Gustafson, The flow of hot saline solutions from vents in the sea floor-some implications for exhalative massive sulfide and other ore deposits, Econ. Geol. 73 (1978) 1082-1100.
3 C.F. Chen and J.S. Turner, Crystallization in a doublediffusive system, J. Geophys. Res. 85 (1980) 2573-2593.

4 J.S. Turner, A fluid-dynamical model of differentiation and layering in magma chambers, Nature 285 (1980) 213-215.

5 A.R. McBirney, Mixing and unmixing of magmas, J. Volcanol. Geotherm. Res. 7 (1980) 357-371.

6 H.E. Huppert and R.S.J. Sparks, Restrictions on the compositions of mid-ocean ridge basalts: a fluid dynamical investigation, Nature 286 (1980) 46-48.

7 H.E. Huppert and R.S.J. Sparks, The fluid dynamics of a basaltic magma chamber replenished by influx of hot, dense ultrabasic magma, Contrib. Mineral. Petrol. 75 (1980) 279289.

8 R.S.J. Sparks, P. Meyer and H. Sigurdsson, Density variation amongst mid-ocean ridge basalts: implications for magma mixing and the scarcity of primitive lavas, Earth Planet. Sci. Lett. 46 (1980) 419-430.

9 E.W. Washburn, ed., International Critical Tables (McGraw-Hill, New York, N.Y., 1929).

10 R. Kremann and A. Žitek, Die Bildung von Konversionssalpeter aus Natronsalpeter und Pottasche vom Standpunkt der Phasenlehre, Monatsh. Chem. 30 (1909) 311-340.

11 J.S. Turner, Buoyancy Effects in Fluids (Cambridge University Press, Cambridge, 1979).

12 H.E. Huppert, On the stability of a series of double-diffusive layers, Deep-Sea Res. 18 (1971) 1005-1021.

13 J.S. Turner, The coupled turbulent transports of salt and heat across a sharp density interface, Int. J. Heat Mass Trans. 8 (1965) 759-767.

14 H.E. Buckley, Crystal Growth (Wiley, New York, N.Y., 1951).

15 J.S. Turner, Jets and plumes with negative or reversing buoyancy, J. Fluid Mech. 26 (1966) 779-792. 